\title{
O PATHE PROJETIVO E EFETIVO E O ENSINO DE LÍNGUA INGLESA NA BNCC
}

\section{PROJECTIVE AND EFFECTIVE PATHE AND ENGLISH LANGUAGE TEACHING AT BNCC}

\section{RICCI, Isadora de Castro Penholato}

Mestranda no Programa de Pós-Graduação em Linguística da Universidade de Franca/UNIFRAN.

E-mail: isapenholato@gmail.com

\section{FERRAZ, Luana}

Doutora em Língua Portuguesa pela Pontifícia Universidade Católica de São Paulo

Docente do Programa de Pós-Graduação em Linguística da Universidade de Franca/UNIFRAN

E-mail: luferraz22@hotmail.com

ORCID ID: https://orcid.org/0000-0002-3208-7863

\section{BORGES, Marilurdes Cruz}

Doutora em Linguística e Língua Portuguesa pela Unesp/Araraquara.

Docente dos Programas de Pós-Graduação em Linguística e em Promoção de Saúde da Universidade de Franca/UNIFRAN

E-mail: marilurdescruz@gmail.com

ORCID ID: https://orcid.org/0000-0002-0602-9838

Aprender a língua inglesa propicia a criação de novas formas de engajamento e participação dos alunos em um mundo social cada vez mais globalizado e plural, em que as fronteiras entre países e interesses pessoais, locais, regionais, nacionais e transnacionais estão cada vez mais difusas e contraditórias.

(Base Nacional Comum Curricular - BNCC)

\section{RESUMO}

O presente artigo tem como objetivo principal entender quem é o auditório visado pelo texto da Base Nacional Comum Curricular, especificamente no componente curricular língua inglesa. O que se pode perceber é que, com o advento da BNCC, em 2018, o ensino da disciplina língua inglesa, componente curricular obrigatório a partir do Ensino Fundamental - Anos Finais -, é repensado, levando-se em consideração não apenas mudanças na própria sociedade, que tem, na língua inglesa, um idioma vastamente usado ao redor do mundo, mas também pensando no auditório que receberá essa Base e que dela fará uso, bem como dos beneficiários finais das propostas apresentadas no documento, prioritariamente os jovens estudantes brasileiros que se conectam ao mundo por meio da Internet e 
de todos os aplicativos e redes sociais cujo acesso se dá ao toque de um dedo. É pensando nesse auditório - professores e alunos - que se pode perceber a construção do discurso, cuja finalidade é persuadi-lo acerca da importância do ensino-aprendizagem da língua inglesa, por meio do desenvolvimento de conhecimentos, competências e habilidades para formar cidadãos capazes de compreender, refletir sobre, avaliar e, então, modificar a realidade em que se vivem.

Palavras-chave: língua inglesa; BNCC; retórica; pathe projetivo e efetivo.

\section{ABSTRACT}

The present article has as main aim to understand whom the audience targeted by the text of the "Base Nacional Comum Curricular" is, specifically in the curricular component English language. What can be noticed is that, with the BNCC's advent, in 2018, the English language teaching, mandatory curricular component since Elementary School - Final Years -, is reconsidered, taking into account not only the changes in the society itself, which has, in English, a language extensively used all over the world, but also the final beneficial of the proposals presented in the document, especially the young Brazilian students that connect themselves through the Internet and through the all apps and social networks whose access is done at the touch of their fingertips. It is thinking about this audience - teachers and students - that it is possible to notice the discourse construction, whose aim is to persuade them about the English language teaching-learning importance, through the development of knowledge, competencies and abilities in order to form citizens capable of understand, reflect about and then change the reality where they live in.

Keywords: English language; BNCC; rhetoric; projective and effective pathe.

\section{INTRODUÇÃO}

É fato que a língua inglesa tem um papel importante nas sociedades do século XXI. Tendo-se em vista todo o processo de globalização pelo qual o mundo passou, bem como a instituição dos Estados Unidos da América como o país de maior hegemonia mundial, é natural que o idioma seja destaque ao redor do mundo, sendo usado como meio de comunicação em diferentes situações.

No Brasil, o ensino do idioma, na Educação Básica, sempre foi pautado no ensino das habilidades relacionadas à escrita e à leitura, tendo por foco, na maioria das vezes, a tradução de textos do inglês para o português. Essa realidade foi mudando ao longo do tempo e, hoje, sabese que o conhecimento da língua inglesa vai muito além do conhecimento que se tem de sua estrutura e de seu léxico. Ser fluente na língua inglesa 
é ser capaz de estabelecer comunicação eficientemente em diferentes contextos, e isso depende de outras habilidades para além de escrita e leitura.

Assim, em 2018, o Governo Federal homologou a Base Nacional Comum Curricular e, com seu advento, algumas mudanças foram pensadas para o componente curricular língua inglesa para os anos escolares em que seu ensino é obrigatório.

Tais mudanças vão ao encontro da demanda global por pessoas que sejam capazes de se comunicar em um mundo em que a língua inglesa deixa de ser mera língua estrangeira e passa a ser língua franca. Mais do que isso, a BNCC propõe que, por meio do ensino de língua inglesa, um cidadão consciente de seus direitos e deveres seja formado e que esse cidadão seja capaz de agir acerca da realidade em que vive, modificandoa.

A partir dessas reflexões e constatações, então, estabelece-se esta pergunta: quem é o auditório previsto pelo texto-base da Base Nacional Comum Curricular, especificamente no componente curricular língua inglesa, e como a sua adesão ao discurso da Base pode influenciar a formação de sujeitos na Educação Básica? O presente artigo tem a intenção de responder a essa questão à luz da Retórica, de Aristóteles, e dos acréscimos feitos a essa tradição pelo filósofo contemporâneo Michel Meyer. Para tanto, este trabalho apresenta, inicialmente, um estudo sobre como a BNCC trata o componente curricular língua inglesa para, na sequência, discutir sobre a influência dos pathe projetivo e efetivo desse documento na formação do sujeito bilíngue.

\section{A BNCC E O COMPONENTE CURRICULAR LÍNGUA INGLESA}

A Educação Básica, no Brasil, é regida por algumas legislações, como, por exemplo: a Lei de Diretrizes e Bases da Educação - a LDB (Lei no 9.394/96), as Diretrizes Curriculares Nacionais e, mais recentemente, a Base Nacional Comum Curricular, também denominada BNCC, cuja homologação deu-se no ano de 2018.

No tocante, especificamente, à BNCC, o que se pode mencionar é que esta tem o objetivo de elencar as aprendizagens essenciais a cada etapa da Educação Básica, a saber: Educação Infantil, Ensino Fundamental (Anos Iniciais e Anos Finais) e, ainda, Ensino Médio. Menciona a página inicial da BNCC na Internet:

A Base estabelece conhecimentos, competências e 
habilidades que se espera que todos os estudantes desenvolvam ao longo da escolaridade básica. Orientada pelos princípios éticos, políticos e estéticos traçados pelas Diretrizes Curriculares Nacionais da Educação Básica, a Base soma-se aos propósitos que direcionam a educação brasileira para a formação humana integral e para a construção de uma sociedade justa, democrática e inclusiva. (BRASIL, 2021, s/p.)

O que o documento determina é que, ao final da Educação Básica, o aluno tenha desenvolvido dez competências gerais básicas, "[...] que consubstanciam, no âmbito pedagógico, os direitos de aprendizagem e desenvolvimento" (BRASIL, 2018, p. 10). Ao propor essas competências, espera-se que se possa desenvolver, ao longo dos anos, uma sociedade mais justa, humana e, ainda, sustentável, conforme menciona o próprio documento. A Figura 1, apresentada a seguir, mostra essas dez competências.

Figura 1 - As dez competências gerais da BNCC

\section{COMPETÊNCIAS GERAIS DA NOVA BNCC}
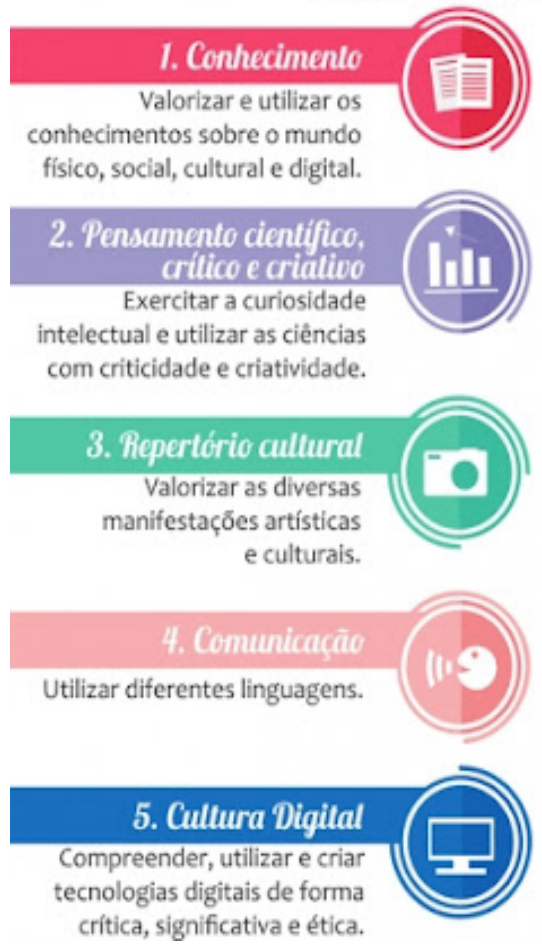
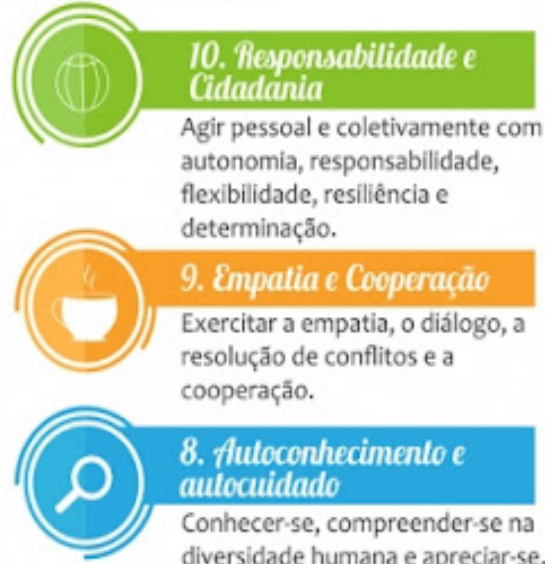

8. Autoconhecimento e autocuidado

Conhecer-se, compreender-se na diversidade humana e apreciar-se.
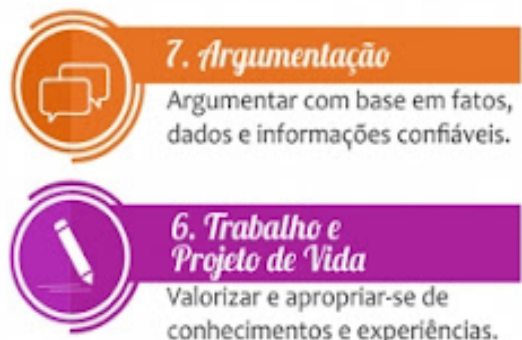

6. Trabalhoe

Projelo de Vida

Valorizar e apropriar-se de

conhecimentos e experiências.

Fonte: Inep (2021). 
No que diz respeito, especificamente, ao componente curricular língua inglesa, este é obrigatório a partir do $6^{\circ}$ ano do Ensino Fundamental até o final do Ensino Médio, conforme estabelece a Lei de Diretrizes e Bases da Educação (LDB - Lei no 9.394/96):

$\S 40$ Os currículos do ensino médio incluirão, obrigatoriamente, o estudo da língua inglesa [...]. (Incluído pela Lei no 13.415, de 2017)

$\S 5^{\circ}$ No currículo do ensino fundamental, a partir do sexto ano, será ofertada a língua inglesa. (Redação dada pela Lei no 13.415, de 2017). (BRASIL, 2021)

Desse modo, como componente curricular obrigatório, a língua inglesa tem seu papel de importância na sociedade globalizada em que se vive atualmente. Inclusive, a BNCC ressalta a sua importância:

Aprender a língua inglesa propicia a criação de novas formas de engajamento e participação dos alunos em um mundo social cada vez mais globalizado e plural, em que as fronteiras entre países e interesses pessoais, locais, regionais, nacionais e transnacionais estão cada vez mais difusas e contraditórias. Assim, o estudo da língua inglesa pode possibilitar a todos o acesso aos saberes linguísticos necessários para engajamento e participação, contribuindo para o agenciamento crítico dos estudantes e para o exercício da cidadania ativa, além de ampliar as possibilidades de interação e mobilidade, abrindo novos percursos de construção de conhecimentos e de continuidade nos estudos. (BRASIL, 2018, p. 243)

Como se pode observar, o documento prevê que o aprendizado de língua inglesa é essencial para o cidadão que se deseja formar atualmente. $\mathrm{E}$, para alcançar esse objetivo, a BNCC, no componente curricular língua inglesa, está fundada em três implicações básicas.

A primeira - e principal - está atrelada ao fato de que a BNCC deixa de perceber a língua inglesa como uma língua estrangeira, falada apenas por países hegemônicos, como Estados Unidos da América e Inglaterra, e passa a ser entendida como língua franca, ou seja, uma língua falada por diversas pessoas, em diversos contextos, ao redor de todo o globo. A esse respeito, menciona:

O conceito [de língua franca] não é novo e tem sido recontextualizado por teóricos do campo em estudos recentes que analisam os usos da língua inglesa no mundo 
contemporâneo. Nessa proposta, a língua inglesa não é mais aquela do "estrangeiro", oriundo de países hegemônicos, cujos falantes servem de modelo a ser seguido, nem tampouco trata-se de uma variante da língua inglesa. Nessa perspectiva, são acolhidos e legitimados os usos que dela fazem falantes espalhados no mundo inteiro, com diferentes repertórios linguísticos e culturais, o que possibilita, por exemplo, questionar a visão de que o único inglês "correto" - e a ser ensinado é aquele falado por estadunidenses ou britânicos. (BRASIL, 2018, p. 243)

Ao conceber a língua inglesa como língua franca, a BNCC também faz referência à questão do letramento, ou multiletramentos, sendo essa a segunda implicação. Como a própria BNCC (2018) consigna, a língua inglesa é usada em meios híbridos, para comunicação de diferentes pessoas, em diferentes contextos de fala. Assim, é possível que o falante leve em conta a fluidez dessa língua e pense em novos jeitos de se expressar por meio da língua inglesa. A BNCC (BRASIL, 2018, p. 244) ainda diz o seguinte:

[...] saber a língua inglesa potencializa as possibilidades de participação e circulação - que aproximam e entrelaçam diferentes semioses e linguagens (verbal, visual, corporal, audiovisual), em um contínuo processo de significação contextualizado, dialógico e ideológico. Concebendo a língua como construção social, o sujeito "interpreta", "reinventa" os sentidos de modo situado, criando novas formas de identificar e expressar ideias, sentimentos e valores.

Finalmente, a terceira implicação está atrelada às abordagens de ensino de língua inglesa. Como língua franca, o professor de língua inglesa deve repensar suas práticas de ensino, entendendo e ensinando ao aluno as variações que ocorrem dentro do idioma não como exceções, mas como recursos existentes e possíveis de serem empregados em contextos comunicacionais. É preciso entender que não há um inglês ideal ou, ainda, melhor de ser ensinado. Assinala a BNCC (BRASIL, 2018, p. 244):

Em outras palavras, não queremos tratar esses usos como uma exceção, uma curiosidade local da língua, que foge ao "padrão" a ser seguido. Muito pelo contrário - é tratar usos locais do inglês e recursos linguísticos a eles relacionados na perspectiva de construção de um 
repertório linguístico, que deve ser analisado e disponibilizado ao aluno para dele fazer uso observando sempre a condição de inteligibilidade na interação linguística.

Essas três implicações para o ensino de língua inglesa no Brasil levam aos cinco eixos organizadores do componente curricular, a saber: Oralidade, Leitura, Escrita, Conhecimentos Linguísticos e Dimensão Intercultural (BNCC, 2018). Aqui, observa-se, mais uma vez, uma mudança de postura frente à disciplina no Brasil. Se, antes, apenas leitura e escrita eram privilegiadas, em um ensino cuja base era a tradução de textos; hoje, além destas, a oralidade também é levada em consideração, pensando-se, como se deve supor, na questão da língua inglesa como língua franca, plural, falada em um mundo globalizado por diferentes pessoas.

Já a presença do eixo "Conhecimentos Linguísticos" vai ao encontro do que se considera ser a língua inglesa na atualidade, propondo que, para além de pensar no que seja certo e errado na língua inglesa, o aluno seja capaz de refletir sobre a questão da variação linguística e dos usos da língua, avaliando as estruturas que podem ser utilizadas em contextos diversos. De acordo com a BNCC (2018, p. 247), esse eixo "[...] consolidase pelas práticas de uso, análise e reflexão sobre a língua, sempre de modo contextualizado, articulado e a serviço das práticas de oralidade, leitura e escrita".

Finalmente, o eixo "Dimensão Intercultural" vem ao encontro do fato de que, ao aprender a língua inglesa, o aluno será capaz de "[...] problematizar os diferentes papéis da própria língua inglesa no mundo, seus valores, seu alcance e seus efeitos nas relações entre diferentes pessoas e povos, tanto na sociedade contemporânea quanto em uma perspectiva histórica" (BNCC, 2018, p. 247). É por meio do diálogo com diferentes pessoas, com diferentes repertórios culturais e linguísticos, que o aluno será capaz de refletir e construir sua própria identidade. Desse modo, ao entrar em diálogo com o outro, cuja história, ideologia e vivências são diferentes, é possível que o sujeito incorpore em sua própria história, ideologia e vivências aquilo que ouviu do outro. Vê-se, portanto, que é nesse contato, nesse diálogo com o outro que se é possível modificar a construção do sujeito do século XXI.

Por meio de todo esse histórico, o que se pode observar é que o advento da Base Comum Curricular (2018) muda os rumos do ensino da língua inglesa da Educação Básica no país, mudança essa necessária diante da realidade do mundo globalizado em que se vive hoje, no qual o domínio da língua inglesa é fundamental para as interações sociais de diferentes sujeitos, cuja cultura e repertório linguístico podem ser refletidos no uso 
da língua.

Ao se ter esse documento norteador do ensino do idioma no país, questiona-se sobre como os oradores desse discurso (organizadores e redatores da BNCC) constroem a(s) imagem(ns) de seu(s) auditório(s) (o público a quem ele se destina). Isto é o que será discutido e apresentado no tópico seguinte.

\section{O(S) AUDITÓRIO(S) DA BNCC - LÍNGUA INGLESA}

Antes de se iniciar a análise aqui proposta, é preciso fazer algumas explanações acerca do que é a Retórica aristotélica e, ainda, fazer algumas reflexões sobre como se dá o processo de comunicação segundo esse filósofo.

De acordo com Aristóteles (2015, p. 95), é possível entender a Retórica como "[...] a capacidade de descobrir o que é adequado a cada caso com o fim de persuadir". E esse processo, como se pode supor, ocorrerá por meio do discurso, conforme menciona o próprio Aristóteles (2015).

Figueiredo (2020) assegura que, para o filósofo, o processo de comunicação está centrado em um tripé, composto pelo ethos, pelo pathos e pelo logos, entendendo-se por ethos a instância do discurso relacionada ao orador, à pessoa que o profere; por pathos, àquela vinculada ao auditório, a quem o discurso é dirigido e, finalmente, por logos, ao discurso em si, a como os argumentos mobilizados pelo orador na defesa de sua tese tomam forma em diferentes linguagens.

Desse modo, ao proferir um discurso, é importante que o orador conheça bem o auditório a quem ele se refere, seus valores, suas crenças e os afetos que podem, nele, ser despertados, a fim de que seu discurso possa convencê-lo ou mesmo persuadi-lo. Conforme menciona Figueiredo (2020, p. 40), o pathos, para além de uma instância física, é também o "[...] conjunto de emoções [...] presentes" no auditório.

Considerando-se a BNCC, especificamente no que trata o componente curricular língua inglesa, o que se pode observar é que o pathos se refere a todos aqueles que lidarão com essa disciplina específica do currículo escolar, desde os diretores das unidades de Educação Básica públicas e privadas, os professores que lecionam esse componente curricular em salas de aula no Brasil afora até, por que não, os alunos que estão em sala de aula e que precisarão estudar essa disciplina ao longo de sua vida escolar.

Trata-se, portanto, do que Meyer (2007) denomina pathos projetivo, isto é, de um auditório imaginado pelo orador, aqui representado pelo 
corpo de especialistas que redigem o documento. Esse orador constrói um "auditório sob medida", que percebe uma problemática, uma questão a ser respondida, e se esforça por compreendê-la. Nesse contexto, a BNCC materializa a resposta legitimada que busca responder às dúvidas de gestores, professores e alunos da Educação Básica.

Premido pelas transformações econômicas, sociais, culturais e tecnológicas do mundo contemporâneo, o auditório previsto pela BNCC sente insegurança e busca alternativas para fazer face a novas demandas. Assim, espera-se que recorra ao documento, elaborado por um orador fidedigno, para encontrar formas de reconstruir seus saberes e adequar suas práticas. Desde que confirmado esse cenário, a Base se propõe como um argumento de autoridade, a síntese de uma reflexão e um ponto de apoio para as deliberações de estudantes e profissionais da Educação que procuram desenvolver práticas de ensino-aprendizagem profícuas e condizentes com as exigências da contemporaneidade. Se movido por esses valores, o auditório tende a encontrar na BNCC a confiança de que necessita para alterar seus julgamentos a respeito do ensino e da aprendizagem da língua inglesa e para agir no estabelecimento de novas prerrogativas intelectivas e comportamentais.

Naturalmente, o auditório esperado, projeto pelo orador, pode não corresponder ao auditório efetivo. Essa defasagem pode ser negativa ou positiva. Quando negativa, temos a ruptura, o choque entre os valores do auditório real e as respostas oferecidas. Nesse caso, a decisão precisa ser arbitrada por um juiz externo, o Ministério da Educação, que determina a normatividade do discurso. Quando positiva, garante-se, pelo potencial argumentativo do documento, o movimento de emulação. Ainda que não buscasse uma resposta em que apoiar qualquer mudança no que respeita às práticas de ensino-aprendizagem de língua inglesa, ou mesmo que seus valores e opiniões até então o incitassem a advogar em direção contrária, o auditório se sente persuadido por uma argumentação que crê sensata e honestamente comprometida com a construção de uma sociedade mais justa, democrática e inclusiva e se esforça por cumprir com suas recomendações.

O que se percebe, no texto da BNCC, é um processo argumentativo que tenta não apenas convencer, mas persuadir seu público de que as mudanças ali propostas são, para além de necessárias, benéficas aos professores e aos estudantes do idioma. Isso pode ser percebido nas primeiras linhas do texto:

Aprender a língua inglesa propicia a criação de novas formas de engajamento e participação dos alunos em um mundo social cada vez mais globalizado e plural, em que 
as fronteiras entre países e interesses pessoais, locais, regionais, nacionais e transnacionais estão cada vez mais difusas e contraditórias. Assim, o estudo da língua inglesa pode possibilitar a todos o acesso aos saberes linguísticos necessários para engajamento e participação, contribuindo para o agenciamento crítico dos estudantes e para o exercício da cidadania ativa, além de ampliar as possibilidades de interação e mobilidade, abrindo novos percursos de construção de conhecimentos e de continuidade nos estudos. (BRASIL, 2018, p. 243)

Observa-se, aqui, que, ao construir seu discurso, o orador usa o argumento de que o conhecimento de um idioma tão difuso na sociedade global pode abrir novas oportunidades para seu auditório, possibilitandoIhe acesso a novas oportunidades para sua vida. Ser fluente na língua inglesa pode, de acordo com o discurso proferido, ser um marco na vida de quem 0 aprende, pois possibilitará novas interações, novas oportunidades sociais, especialmente sabendo-se que, hoje, no mundo todo, fala-se essa língua. Ressalta-se, assim, uma face do ethos à qual denominamos eúnoia e que aponta para a benevolência do orador. Essa virtude do ethos, quando percebida pelo auditório, permite que este suponha que o orador aconselha para o seu bem e não apenas em interesse próprio. Desse modo, configura-se um importante passo na conquista da confiança do auditório e, por consequência, do acordo pretendido.

Pode mencionar-se, também, que o orador tenta persuadir seu auditório de que o aprendizado da língua inglesa poderá contribuir com a aquisição de novas competências, facultando a inserção do educando como cidadão em um mundo globalizado, cuidando para que a sociedade seja cada vez mais sustentável, o que vai ao encontro, por exemplo, da Agenda 2030 (ONU, 2015). É importante, aqui, mencionar que esses argumentos e que a ligação com a Agenda 2030 estão presentes em todo o texto da BNCC, e não apenas no texto específico do componente curricular língua inglesa. Verifica-se, assim, a constituição discursiva de um orador sensato e honesto, que assume postura justa e apropriada e que orienta o auditório na tomada de decisões coerentes. Constroem-se, desse modo, mais duas importantes virtudes desse orador: a phrónesis, ou "sabedoria prática"; e a areté, o discernimento moral.

Contudo, não parece tão simples persuadir o auditório e despertar, nele, a confiança de que a língua inglesa será bem recebida pelos estudantes, uma vez que o idioma é visto por muitos como de difícil acesso e compreensão, distante da realidade do dia a dia de muitos cidadãos brasileiros. O que a BNCC propõe é a mudança do status de língua 
estrangeira para língua franca, mostrando aos gestores e professores e, por conseguinte, aos seus próprios auditórios que, hoje, o idioma não pertence apenas a países hegemônicos como os Estados Unidos da América ou, ainda, Inglaterra. Hoje, a língua inglesa está presente em diversos espaços sociais, sendo usada em contextos os mais diversos possíveis, como, por exemplo: nas redes sociais, que colocam o sujeito em contato com pessoas ao redor de todo o globo; os jogos em rede, nos quais é também possível a interação; os aplicativos de vídeo e música; as plataformas de streaming, dentre tantos outros.

Seguindo na apresentação da nova proposta para o componente curricular Língua Inglesa, mostra-se que a própria prática pedagógica de sala de aula muda por meio dos multiletramentos e do ensino por meio de diferentes linguagens - textos escritos, músicas, vídeos, memes, entre tantas outras linguagens presentes no dia a dia do estudante. Observa-se, aqui, que há a intenção de aproximar a língua inglesa da realidade do auditório, mostrando-Ihe que a língua inglesa está presente em seu dia a dia, bastando naturalizar o seu uso e valer-se dele em propostas didáticas inovadoras.

A BNCC também promove uma reflexão sobre as adequações e inadequações à norma-padrão ao afirmar que os alunos terão contato não apenas com a norma-padrão do idioma, como também com as variações linguísticas presentes na língua inglesa. Essa posição abre a possibilidade de aproximar ainda mais esse idioma do auditório, mostrando-Ihe que a língua que se ensina e que se aprende é aquela usada diariamente por grande parte das pessoas, em músicas, em sites, em memes, enfim, em meios diversos, incluindo situações formais de comunicação, a fim de que seja possível comunicar-se fluentemente. Assim consigna a BNCC:

[...] é tratar usos locais do inglês e recursos linguísticos a eles relacionados na perspectiva de construção de um repertório linguístico, que deve ser analisado e disponibilizado ao aluno para dele fazer uso observando sempre a condição de inteligibilidade na interação linguística. (BRASIL, 2018, p. 242)

Ao estruturar o texto em eixos organizadores, e não mais em habilidades, e ao incluir, aí, o eixo da Oralidade, o orador coloca a língua inglesa como um idioma importante de ser conhecido não apenas em sua modalidade escrita, mas, também, na falada, tendo-se em vista que, hoje, não basta apenas traduzir textos ou ter a competência de compreendê-los, mas deve-se ter algum nível de compreensão auditiva e também de fala, especialmente com o advento de plataformas virtuais e de redes sociais 
que podem facilitar o acesso a discursos falados de diferentes pessoas, podendo-se comunicar com elas.

Também se deve mencionar o fato de que o eixo "Dimensão Intercultural" vem mostrar a importância que tem o conhecimento a respeito de outras culturas e de outros povos do mundo e como esse conhecimento pode possibilitar ao auditório de profisssionais da Educação e/ou estudantes a reflexão e o agir sobre sua própria cultura e identidade, sendo possível agir e modificar o seu entorno.

Assim, o discurso construído pelo orador especializado constituído no documento tem a intenção de mostrar ao auditório que, por meio do ensino-aprendizagem de um novo idioma, há a possibilidade de aquisição de competências diversas, as quais the possibilitarão refletir sobre a sociedade que o rodeia e, então, agir sobre ela, modificando-a. Indo além, é possível que esse auditório, ao modificar suas práticas, promova uma transformação de sua própria realidade, possibilitando a si (gestor e professor) e aos demais (alunos) formas de acesso a novas informações e a novos conhecimentos que tornem possível a interação com novas pessoas, de culturas diferentes da sua.

\section{CONSIDERAÇÕES FINAIS}

O discurso que é construído por meio do texto da BNCC tem como auditório os jovens estudantes brasileiros do século XXI e os profissionais de Educação que os receberão nas salas de aula da Educação Básica de escolas públicas e privadas de todo o Brasil. Esse jovem tem acesso, em sua maioria, a diferentes mídias, cujas linguagens são as mais diversas; ele está sempre conectado à Internet, e esse acesso abre-lhe a possibilidade de entrar em diálogo com outras pessoas, de lugares completamente diferentes e com culturas as mais diversificadas.

Pensando-se, assim, nas demandas sociais que são apresentadas, por exemplo, pela Agenda 2030, é preciso que os profissionais da Educação se preocupem com a formação desse jovem, a fim de que ele se torne capaz de realmente conhecer, avaliar, refletir e agir sobre a realidade que o cerca, modificando-a. Para tanto, é necessário que ele adquira competências que o façam ser capaz de realizar essas mudanças. O aprendizado da língua inglesa mostra-se, pois, importante nesse processo, já que, com o advento da globalização, esse idioma tornou-se o idioma do mundo globalizado, sendo usado em diversas situações de comunicação ao redor de todo o globo.

Também é perceptível a questão da mudança da abordagem de ensino proposta pela BNCC, que sai da já ultrapassada visão de que a 
língua inglesa ensinada na escola é aquela com vistas à tradução de textos e passa a ser aquela usada em vídeos, em memes das redes sociais, em músicas que podem ser ouvidas em aplicativos de streaming, tudo a um toque do dedo, por meio dos smartphones.

Por meio desse enfoque, tem-se a intenção de aproximar esse idioma dos valores de um pathos projetivo, visado pelo orador, em suposta congruência com o auditório real, ou pathos efetivo, mostrando a ele que a língua inglesa está em todo o lugar e que é usada o tempo todo para fins de entretenimento, informação, negociação, aprendizado, entre tantos outros, e que esses usos constituem precioso material para a proposição de interessantes estratégias pedagógicas.

O multiletramento apresentado pelo documento também é importante ao considerar não apenas a norma-padrão como foco do ensino da língua inglesa, sendo legitimados e ensinados outros usos que os falantes fazem do idioma, num processo que aproxima esse idioma da realidade de vida do auditório e de seus futuros interlocutores.

Tais mudanças são, por conclusão, importantes de serem não apenas feitas no papel, mas concretizadas em sala de aula. Para tanto, devem pautar-se na correspondência entre o pathos projetivo e o pathos efetivo, que realmente apreciará o discurso e o tomará como ponto de partida para a execução de novas práticas, que pretensamente beneficiarão os estudantes a que nos referimos, por darem ocasião a um aprendizado muito mais próximo de sua realidade. É por meio do discurso proferido pelo ethos legitimado, construído na BNCC, e da influência que ele exerce na transformação das práticas pedagógicas de outros tantos oradores espalhados em diferentes salas de aula ao redor do Brasil que será possível proporcionar a outros auditórios a possibilidade de, como já se mencionou aqui, não apenas conhecer, mas refletir, avaliar e, finalmente, modificar a si e à sociedade em que se vive.

\section{REFERÊNCIAS}

ARISTÓTELES. Retórica. 2. ed. Lisboa: Imprensa Nacional: Casa da Moeda, 2005.

BRASIL. Aprender Inglês: meu novo mundo. Disponível em:

http://basenacionalcomum.mec.gov.br/implementacao/ praticas/cadernode-praticas/ensino-medio/116-aprender-ingles-meu-novo-mundo. Acesso em: 24 abr. 2021.

BRASIL. Base Nacional Comum Curricular. Educação é a base. Brasília, 
17 de dezembro de 2018. Disponível em: <http://basenacional comum.mec.gov.br/images/BNCC_EI_EF_110518_versaofinal_site.pdf > . Acesso em: 24 abr. 2021.

BRASIL. Lei no 9.394, de 20 de dezembro de 1996. Estabelece as diretrizes e bases da educação nacional. Diário Oficial da União, Brasília, 23 de dezembro de 1996. Disponível em: <http://www.planalto. gov.br/ccivil_03/leis/L9394.htm>. Acesso em: 24 abr. 2017.

\section{INEP. Novas competências da Base Nacional Comum Curricular} (BNCC). Disponível em: <http://inep80anos.inep.gov.br/inep80anos/ futuro/novas-competencias-da-base-nacional-comum-curricular-bncc/79> . Acesso em: 21 nov. 2021.

FIGUEIREDO, M. F. Ampliação e Aplicabilidade Analítica da "Trajetória das Paixões". In: FIGUEIREDO, M. F.; GOMES, A. M; FERRAZ, L. Trajetória das paixões: uma retórica da alma. Grupo PARE. Franca: Unifran, 2020. MEYER, M. A retórica. Trad. Marly N. Peres. São Paulo: Ática, 2007.

ONU. Agenda 2030. 2015. Disponível em: <http://www.agenda2030. com.br/sobre/> Acesso em: 24 abr. 2021.

Recebido em: 06/12/2021

Aceite em: 19/12/2021 